\title{
Investigations of Physical and Rheological Properties of Aged Rubberised Bitumen
}

\author{
Asim Hassan Ali, Nuha S. Mashaan, and Mohamed Rehan Karim \\ Center for Transportation Research, Faculty of Engineering, University of Malaya, 50603 Kuala Lumpur, Malaysia \\ Correspondence should be addressed to Asim Hassan Ali; asim@siswa.um.edu.my
}

Received 27 August 2012; Accepted 15 January 2013

Academic Editor: Dachamir Hotza

Copyright (C) 2013 Asim Hassan Ali et al. This is an open access article distributed under the Creative Commons Attribution License, which permits unrestricted use, distribution, and reproduction in any medium, provided the original work is properly cited.

\begin{abstract}
Several road pavement distresses are related to rheological bitumen properties. Rutting and fatigue cracking are the major distresses that lead to permanent failures in pavement construction. Influence of crumb rubber modifier (CRM) on rheological properties of bitumen binder such as improvement of high and intermediate temperatures is investigated in the binder's fatigue and rutting resistance through physical-rheological changes in this research. The bitumen binders were aged by rolling thin film oven (RTFOT) to simulate short-term aging and pressure aging vessel (PAV) to simulate long-term aging. The effects of aging on the rheological and physical properties of bitumen binders were studied conducting dynamic shear rheometer test (DSR), Brookfield viscometer test, softening point test, and penetration test. The results showed that the use of rubberised bitumen binder reduces the aging effect on physical and rheological properties of the bitumen binder as illustrated through lower aging index of viscosity, lower aging index of $G^{*} / \sin \delta$, and an increase in Tan $\delta$ with crumb rubber modifier content increasing, indicating that the crumb rubber might improve the aging resistance of rubberised bitumen binder. In addition, the results showed that the softening point increment $(\Delta S)$ and penetration aging ratio (PAR) of the rubberised bitumen binder decreased significantly due to crumb rubber modification. Furthermore, the higher crumb rubber content, the lower $G^{*} \sin \delta$ after PAV aging, which led to higher resistance to fatigue cracking bitumen.
\end{abstract}

\section{Introduction}

Several road pavement distresses are related to bitumen properties. Rutting and fatigue cracking are the major distresses that lead to permanent failures in pavement construction. Bitumen is a viscoelastic material; its rheological properties are very sensitive to temperature and rate of loading. In general, road pavement performance properties are mainly affected by the bitumen binder properties; it is well known that the rheological properties and durability of conventional bitumen are not sufficient to resist pavement distresses. A conventional bitumen $80 / 100$ penetration grade is commonly used in Malaysia, and moreover, it is subjected to the high traffic load and hot climate. The use of crumb rubber (waste tyre) in bitumen modification is considered as a sustainable technology which transforms unwanted residue into a new bituminous mixture. Aging is known as a factor influencing the performance and characteristics of bitumen binder. Many factors might contribute to this hardening of the bitumen such as oxidation, volatilisation, polymerization, and thixotropy [1]. Field studies have shown that crumb rubber can improve the bitumen pavement performance [2-5].

Mohamed et al. [6] illustrated the influence of low CRM content on rheological properties of aged bitumen, reporting that the rheological changes in bitumen binder led to improving the mechanical properties of rubberised bitumen binder. In a joint experiment, Abdelaziz and Karim [7] conducted a study on rheological evaluation of aged rubberised bitumen. The results showed that CRM has an obvious significant effect on bitumen rheology by increasing complex shear modulus $G^{*}$ and decreasing phase angle $\delta$. Also, the RTFOT aging results of this study indicated that $G^{*}$ was increased by 1 to 1.5 times for unmodified bitumen and 2.5 times for rubberised bitumen. The PAV test indicated an increase in complex shear modulus which was about 2 and 3 times for unmodified and rubberised bitumen, respectively. 
The applications of rubberised bitumen binders have reported many advantages; for instance improved bitumen resistance to rutting due to high viscosity, high softening point and better resilience, reduction in road pavement maintenance cost, lower fatigue/reflection cracking, and less temperature susceptibility [8]. In general, the application of crumb rubber modified in bitumen binder can improve binder properties by lowering the inherent temperature susceptibility of binders $[9,10]$. The use of crumb rubber modifier with bitumen binder led to enhancing the fatigue resistance $[11,12]$. The improved performance of bitumen rubber pavements compared with conventional bitumen pavements is primarily a result of improved rheological properties of the rubberised bitumen binder.

A study by Aflaki and Memarzadeh [13] investigated the effect of rheological properties of crumb rubber on fatigue cracking at low and intermediate temperatures using different shear methods. The results of this study showed that the high shear blending indicated more influence on improvement of low-temperature properties of rubberised binder than the low shear blending. The mechanism by which binder properties may change at low temperature was presented. This mechanism is referred to as physical hardening occurring at temperatures next to or lower than the glass transition temperature and causes significant hardening of the bitumen binder. Aging influenced the bitumen chemistry and rheology significantly; additionally, the use of the two aging conditions, that is, thin film oven test (TFOT) and rolling thin file oven test (RTFOT) showed a strong correlation and similar severity [14]. The ideal use of bitumen binders as paving materials is dependent on its resistance to the physical change across the range of temperatures encountered in a conventional pavement. Aging significantly changed both the chemical and physical properties of asphalts. Physical properties such as penetration, ductility, viscosity, and stiffness are all affected to some extent by aging [15].

Aging index measurement is one of the most popular procedures used to determine aging susceptibility and provides ranking of different bitumen binders. Aging index is defined as the ratio of a given binder property after aging to that property before aging as shown in (1):

$$
\text { Aging index }=\frac{\text { Bitumen property after aging }}{\text { same property before aging }} \text {. }
$$

1.1. Research Objective and Scope. The primary objective of this research is to evaluate and investigate the influence of crumb rubber content on the rubberised binder's rheological and physical changes subsequent to aging. The secondary objective is to identify the degree of aging in rheological and physical properties of rubberised bitumen and its effect on high-temperature properties (rutting) as well as intermediate temperature (fatigue cracking) through short-term aging test (rolling thin film oven test (RTFOT)) and long-term aging test (pressure aging vessel (PAV)).
TABLE 1: Physical and rheological properties of 80/100 PG bitumen.

\begin{tabular}{lc}
\hline Test properties & Results \\
\hline Viscosity at $135^{\circ} \mathrm{C}(\mathrm{Pa} \cdot \mathrm{s})$ & 0.65 \\
$G^{*} / \sin \delta$ at $64^{\circ} \mathrm{C}(\mathrm{kPa})$ & 1.35 \\
Ductility at $25^{\circ} \mathrm{C}(\mathrm{cm})$ & $>100$ \\
Softening point $\left({ }^{\circ} \mathrm{C}\right)$ & 47 \\
Penetration at $25^{\circ} \mathrm{C}(\mathrm{d}-\mathrm{mm})$ & 88 \\
Ductility after $\mathrm{RTFOT}$ at $25^{\circ} \mathrm{C}(\mathrm{cm})$ & $>100$ \\
RTFOT aged $G^{*} / \sin \delta$ at $64^{\circ} \mathrm{C}(\mathrm{kPa})$ & 6.022 \\
PAV aged $G^{*} \sin \delta$ at $25^{\circ} \mathrm{C}(\mathrm{kPa})$ & 3122.5 \\
\hline
\end{tabular}

TABLE 2: The chemical components of the original bitumen before and after ageing.

\begin{tabular}{lccc}
\hline & Unaged & After RTFOT & After PAV \\
\hline Saturates (\%) & 15.1 & 13.88 & 12.47 \\
Aromatics (\%) & 48.55 & 44.19 & 38.55 \\
Resins (\%) & 26.22 & 28.94 & 31.21 \\
Asphaltenes (\%) & 10.13 & 12.99 & 17.77 \\
\hline
\end{tabular}

TABLE 3: (CRM gradation).

\begin{tabular}{lc}
\hline Sieve $n($ size, $\mathrm{mm})$ & Particle size distribution \\
\hline No. $10(2.00)$ & 100 \\
No. $16(1.180)$ & 100 \\
No. $20(0.850)$ & 100 \\
No. $30(0.600)$ & 97.7 \\
No. $40(0.425)$ & 61.1 \\
No. $50(0.300)$ & 33.9 \\
No. $80(0.180)$ & 12.5 \\
No. $100(0.150)$ & 7.5 \\
No. $200(0.075)$ & 0.0 \\
\hline
\end{tabular}

\section{Experimental Program and Materials}

The base $80 / 100$ penetration grade bitumen was used in this study. Tables 1 and 2 show the properties of base bitumen and the chemical components of original bitumen (before and after aging), respectively. Rubberised bitumen binder was prepared by mixing bitumen $80 / 100$ penetration grade with CRM ( $8 \%$ and $16 \%$ by binder weight) passing the 30 mesh sieve as shown in Table 3 , the propeller mixer used to mix the base bitumen, and the crumb rubber at constant blending conditions of $180^{\circ} \mathrm{C}$ temperature, time of 60 minutes, and velocity of $200 \mathrm{rpm}$.

The samples were aged using the standard rolling thin file oven test (RTFOT) (ASTM D-2872) at a temperature of $163^{\circ} \mathrm{C}$ for $85 \mathrm{~min}$ as short-term aging and pressure aging vessel (PAV) (AASHTO PP1) at $100^{\circ} \mathrm{C}$ and an air pressure of 2.1 Mpa for 20 hours to simulate the long-term aging. To investigate the influence of oxidative aging on rheological changes of rubberised bitumen, the age hardening is evaluated by measuring Brookfield viscosity $\left(135^{\circ} \mathrm{C}\right)$ ASTM D4402, penetration test $\left(25^{\circ} \mathrm{C}\right)$ ASTM D5, softening point test $\left(25^{\circ} \mathrm{C}\right)$ ASTM D36, and dynamic shear (DSR) ASTM D-4 Proposal 
TABLE 4: DSR condition test used in the current study.

\begin{tabular}{lcccc}
\hline $\begin{array}{l}\text { Rheological } \\
\text { parameter }\end{array}$ & $\begin{array}{c}\text { Plate Dia. } \\
(\mathrm{mm})\end{array}$ & $\begin{array}{c}\text { Gap } \\
(\mathrm{mm})\end{array}$ & Sample & $T\left({ }^{\circ} \mathrm{C}\right)$ \\
\hline$G^{*} / \sin \delta$ & 25 & 1 & RTFOT & 76 \\
$G^{*} \sin \delta$ & 8 & 2 & PAV & 31 \\
\hline
\end{tabular}

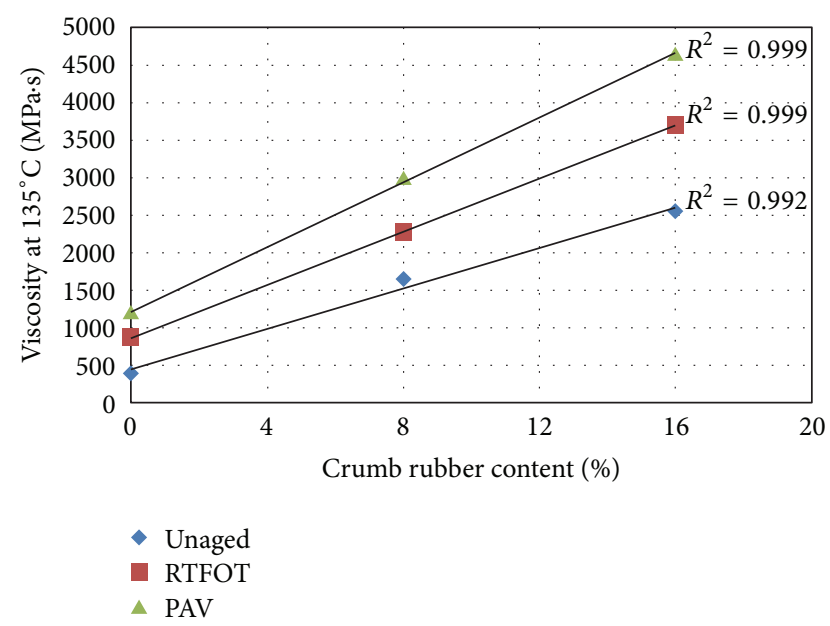

FIGURE 1: Brookfield viscosity results versus crumb rubber content.

P246. In this study, the condition test of DSR test of parallel plate (diameter and gaps), frequency sweep, and the testing temperature for samples during RTFOT and PAV aging are listed in Table 4.

\section{Results and Discussion}

\subsection{Performance Properties at High Temperature}

3.1.1. Brookfield Viscosity at $135^{\circ} \mathrm{C}$. The viscosity of bitumen binders at high temperatures is an important property as it is a good indicator of the binder's ability of pumping through bitumen plant [16]. Figures 1 and 2 show the viscosity results of the rubberised bitumen tested in this study for various rubber contents and aging phases/conditions. As expected, the increase in crumb rubber content led to high viscosity of the rubberised binder. Additionally, the increase in viscosity of aged rubberised bitumen was about 36\% and $44 \%$ for rubber contents of $8 \%$ and $16 \%$, respectively, under RTFOT aging conditions, while the increase in the viscosity under PAV aging values was about $78 \%$ and $82 \%$ for rubber content of $8 \%$ and $16 \%$, respectively. Thus, the increase in crumb rubber content has an obvious effect on aged rubberised bitumen viscosity compared to aged unmodified bitumen with correlation coefficient $R^{2}=0.997$. The reason is the conversion to asphaltenes (the highest molecular component fraction) of the other lower molecular weight asphalt components through oxidation. This is clearly evidenced by molecular weight analysis of asphalts before and after aging as shown in Table 2.

Figure 3 shows VAI of the original bitumen and the rubberised binder after RTFOT and PAV aging. VAI is the

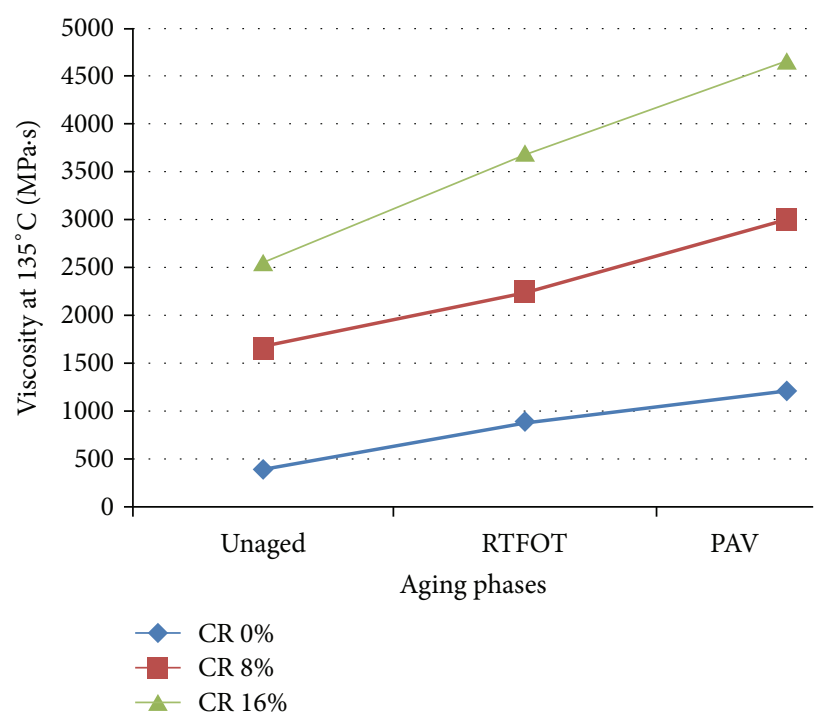

FIGURE 2: Brookfield viscosity results of CRM binders versus aging conditions.

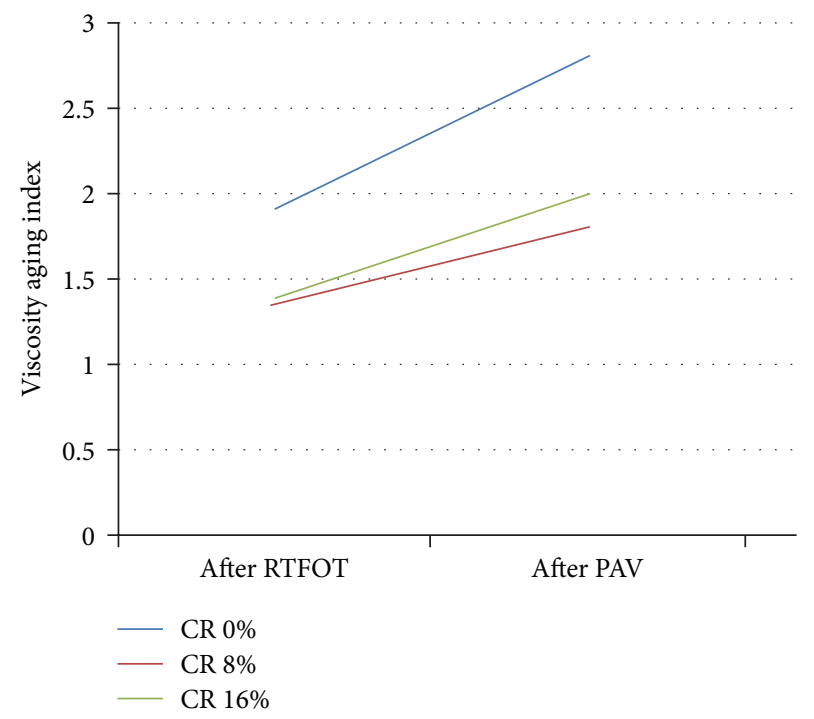

FIGURE 3: VAI of original and rubberised modified bitumen after RTFOT and PAV.

ratio of aged viscosity of the binder to the unaged viscosity of same binder as illustrated in (2) [17]:

$$
\mathrm{VAI}=\frac{V_{\text {aged }}}{V_{\text {unaged }}}
$$

where VAI is the viscosity aging index, $V_{\text {unaged }}$ and $V_{\text {aged }}$ are the viscosities of unaged and aged values of the binder, respectively. This exhibits that viscosity aging index of rubber modified binder is significantly lower than that of unmodified bitumen, thus indicating that the rubberised bitumen would improve the thermooxidative aging properties of bitumen. This result can be explained by the chemical components change of the binder during the aging that led to the increase 


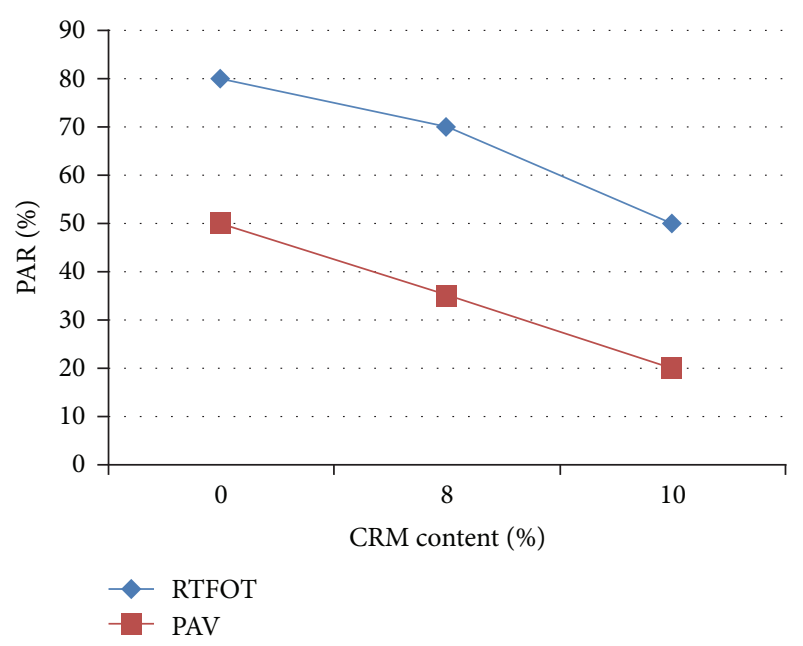

FIGURE 4: Effect of aging on penetration of bitumen binder.

of the asphaltene content which was responsible for increasing the viscosity flow of the bitumen binder. The viscosity aging index reflected better resistance of crumb rubber modified bitumen to aging as it showed lower value after shortterm aging, RTFOT, and long-term aging, PAV, respectively. Thus, the use of viscosity aging index determines the effect of aging of the original bitumen and modified bitumen which provides a much clearer effect of the hardening (aging) rate [17].

3.1.2. Penetration Aging Ratio Results. The penetration aging ratio is an alternative option to show the effects of aging on the physical properties of the bitumen binder. Penetration aging ratio (PAR) can be defined as the ratio of aged penetration value to unaged penetration as illustrated in (3):

$$
\text { PAR }=\left(\frac{\text { penetration }_{\text {aged }}}{\text { penetration }_{\text {unaged }}}\right) \times 100 .
$$

Figure 4 shows the penetration aging ratio of original and rubberised bitumen after rolling thin film oven test and pressure aging vessel test. The results showed that the penetration of unmodified bitumen and rubberised bitumen binders decreased after the two different aging. In addition, the higher crumb rubber content, the lower penetration aging ratio which led to reducing the degree of aging of rubberised bitumen binder. Thus, the crumb rubber addition led to improving the binder resistance to oxidative aging.

3.1.3. Softening Point Increment $(\Delta S)$. The softening point increment can be used as a good indicator to measure the degree of aging, and it can be defined by $\Delta S$ and calculated as shown in (4):

$$
\Delta S=\mathrm{S} . \mathrm{P}_{\text {aged }}-\mathrm{S} . \mathrm{P}_{\text {unaged }}
$$

where $\Delta S$ is the softening point increment, S.P $P_{\text {aged }}$ is aged softening point value, and S.P $\mathrm{P}_{\text {unaged }}$ is the unaged softening point value. Figure 5 shows the effect of crumb rubber

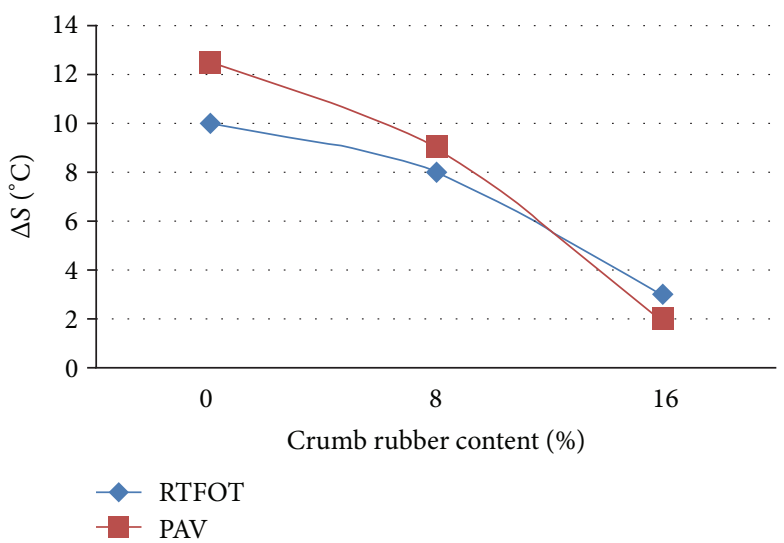

FIGURE 5: Effect of aging on softening point increment of bitumen binder.

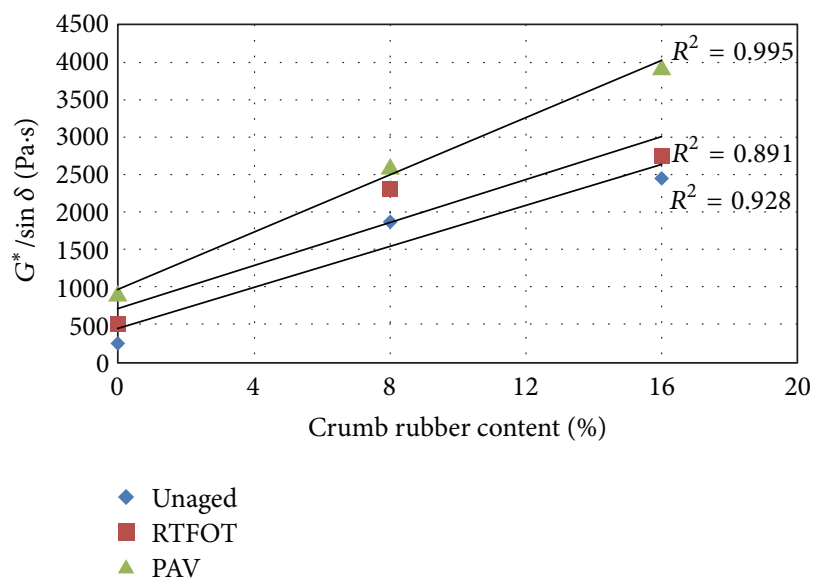

FIGURE 6: $G^{*} / \sin \delta$ results versus crumb rubber content.

modified binder bitumen on softening point changes after RTFOT aging and PAV aging. The softening point results of unmodified bitumen and rubberised bitumen showed an increase after both aging conditions of RTFOT and PAV, respectively, as the rubber content increased, indicating the hardening level of the materials during aging. In comparing the softening point increment $(\Delta S)$ of modified binder with bitumen without crumb rubber modifier, the crumb rubber modified bitumen showed lower $(\Delta S)$ as rubber crumb content was increased. This can be explained by the structural change of molecules in asphalt of fraction content during aging, which led to an increase in the softening point $[17,18]$. Thus, the results of using rubberised bitumen binder have a significant effect on improving the aging resistance and show lower hardening aging which can reduce the oxidative aging resistance of the bitumen.

3.1.4. Influence of Aging on Rheological Properties at $76^{\circ} \mathrm{C}$. The dynamic shear rheometer test was conducted to select the rutting resistance parameter, $G^{*} / \sin \delta$, of the unmodified binder and rubberised bitumen binder were mastered at $76^{\circ} \mathrm{C}$, and the results are shown in Figure 6. Generally, the higher rubber content led to high value of rutting factor, $G^{*} / \sin \delta$, 


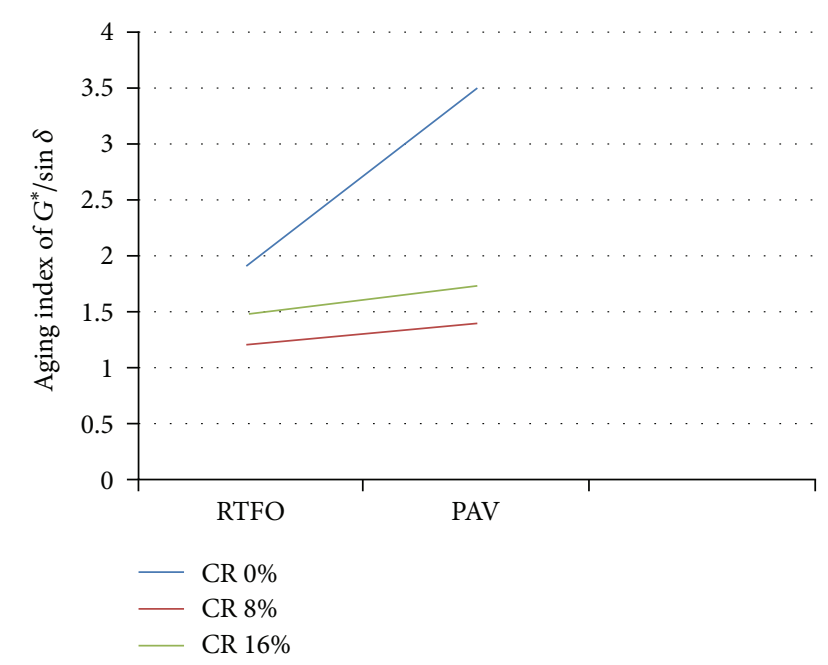

Figure 7: Aging index of $G^{*} / \sin \delta$ of bitumen binder versus CRM content.

for all combinations tested. Additionally, $G^{*} / \sin (\delta)$ of aged rubberised bitumen was about $11 \%$ and $21 \%$ for rubber contents of $8 \%$ and $16 \%$ compared to unaged base binder using RTFOT aging conditions. The increase in the $G^{*} / \sin (\delta)$ was about $38 \%$ and $60 \%$ for samples of $8 \%$ and $16 \%$ rubber content, respectively, compared to unaged base binder using PAV aging conditions. Thus, the increase in crumb rubber content has an obvious effect on rutting factor, $G^{*} / \sin (\delta)$, with correlation coefficient $R^{2}=0.995$. In general, the results of rubberised binder are in tandem with the superpave binder specification of a minimum $G^{*} / \sin \delta$ requirement using RTFOT (2.2 Pa) which showed that the binder with higher $G^{*} / \sin \delta$ value is less susceptible to rutting deformation at high pavement temperatures $[10,19]$. Figure 7 shows the aging index of rutting factor, $G^{*} / \sin \delta$, of original and crumb rubber modified bitumen binder at $76^{\circ} \mathrm{C}$ as calculated by (5) as follows:

$$
\operatorname{AIRF}=\frac{\left(G^{*} / \sin \delta\right)_{\text {aged }}}{\left(G^{*} / \sin \delta\right)_{\text {unaged }}} .
$$

In the case of AIRF as the aging index of rutting factor $\left(G^{*} / \sin \delta\right)_{\text {aged }}$ and $\left(G^{*} / \sin \delta\right)_{\text {unaged }}$ is the $G^{*} / \sin \delta$ value of bitumen binder after and before aging, respectively. The results showed that $G^{*} / \sin \delta$ of bitumen binder with different content of crumb rubber increased after different aging, obviously after PAV aging. Thus, crumb rubber modified bitumen binder showed better resistance to oxidation aging. As displayed in Figure 7, the unmodified binder was of higher AIRF which led the binder to being more susceptible to aging, while modified bitumen shows lower AIFR as crumb rubber increased in the specimen, leading to better aging resistance of modified binder.

Figure 8 shows the effect of aging on loss tangent of bitumen binder after RTFOT aging and PVA aging. The results displayed that the higher the crumb rubber content, the higher aging index of loss tangent, $\operatorname{Tan} \delta$, indicating better aging resistance. The aging ratio of loss tangent is defined as

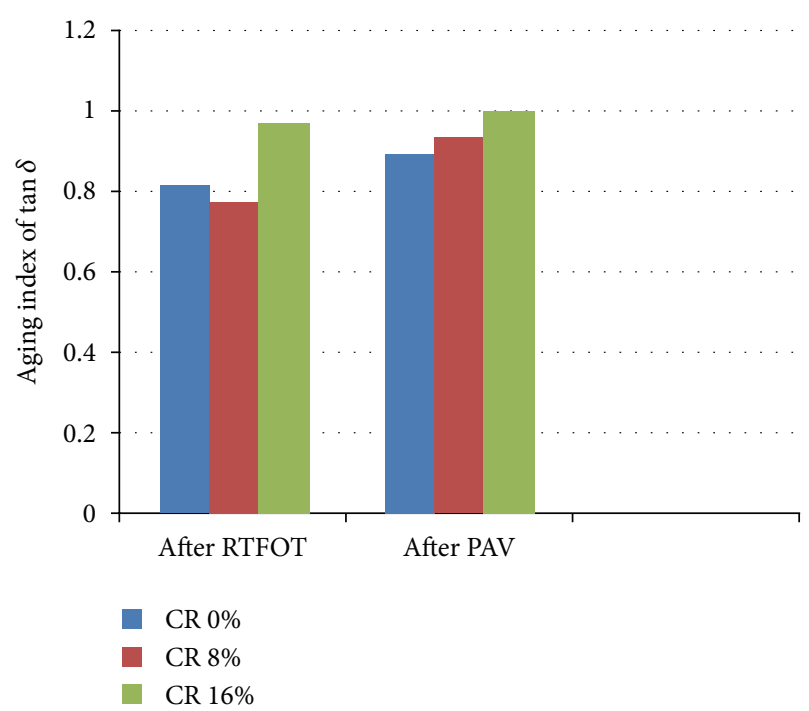

FIGURE 8: Effect of aging on Tan $\delta$ of bitumen binder.

the ratio of aged $\operatorname{Tan} \delta$ to unaged $\operatorname{Tan} \delta$ of the bitumen binder as shown in (6):

$$
\operatorname{Tan} \delta \text { avg. }=\left[\frac{(\operatorname{Tan} \delta)_{\text {aged }}}{(\operatorname{Tan} \delta)_{\text {unaged }}}\right] \times 100,
$$

where $\operatorname{Tan} \delta$ avg. is the average of $\operatorname{Tan} \delta .(\operatorname{Tan} \delta)_{\text {aged }}$ and/ $(\operatorname{Tan} \delta)_{\text {unaged }}$ is the $(\operatorname{Tan} \delta)$ value of bitumen binder after and before aging, respectively. The higher value of aging index $\operatorname{Tan} \delta$ is related to higher elastic behaviour (high in storage modulus $G^{\prime}$ ) since Tan $\delta=G^{\prime \prime} / G^{\prime}$; thus the high-loss tangent of rubberised bitumen led to more elastic behaviour and more solid-like material. This suggests that the rubberised bitumen binder can improve the resistance to oxidative aging.

\subsection{Fatigue Cracking Properties at Intermediate Temperature.} The Strategic Highway Research Program (SHRP) had a maximum value of $5000 \mathrm{kPa}$ for $G^{*} \sin (\delta)$, and low values of these parameters are considered good indicators of fatigue cracking resistance [16]. In this study, the fatigue resistance parameter, $G^{*} \sin (\delta)$ values, of the unaged bitumen and rubberised binders after pressure aging vessel (PAV), were measured using the dynamic shear rheometer (DSR) at $31^{\circ} \mathrm{C}$, and the results are illustrated in Figure 9. In general, the high crumb rubber content led to lower $G^{*} \sin (\delta)$ values of the rubberised bitumen binders. The decrease in the $G^{*} \sin (\delta)$ was about $13 \%$ and $25 \%$ for rubber content of $8 \%$ and $16 \%$, respectively, after pressure aging vessel (PAV), aging conditions, respectively. Thus, the increase in crumb rubber content has an obvious effect on aged rubberised bitumen fatigue parameter, $G^{*} \sin \delta$, with correlation coefficient $R^{2}=$ 0.816 after PAV aging. Owing to the aging, the results showed that the lower the $G^{*} \sin \delta$ value, the less shearing energy loss and the better ability of the fatigue resistance. Also, $G^{*} \sin \delta$ of the modified bitumen is lower than the unmodified bitumen at temperature of $31^{\circ} \mathrm{C}$, indicating that rubberised bitumen 


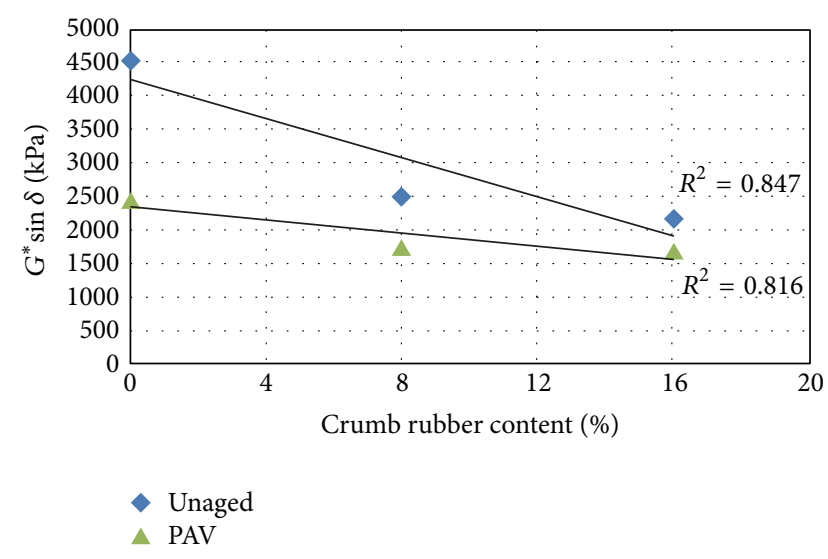

FIGURE 9: $G^{*} \sin \delta$ results versus crumb rubber content.

binder would improve the fatigue resistance of bitumen as a result of introduction of crumb rubber modifier (CRM).

\section{Conclusion}

After the introduction to the problem, a review of the literature, and analysis and discussion of the findings, this section intends to summarise the overall conclusions achieved through this research. Therefore, the significant findings of the current study are as follows.

(1) The results showed that the use of rubberised bitumen binder reduced the aging effect on physical and rheological properties of the bitumen binder as illustrated through lower aging index of viscosity, lower aging index of $G^{*} / \sin \delta$ at $76^{\circ} \mathrm{C}$, and an increase in Tan $\delta$ with increased crumb rubber modifier content, indicating that the antioxidant released in asphalt from the tire rubber particles is a significant factor in reducing the aging effect as correctly observed by the data results.

(2) In addition, the results showed that the softening point increment $(\Delta S)$ and penetration aging ratio (PRA) of the rubberised bitumen binder decreased significantly due to crumb rubber modification.

(3) The aging index of viscosity reflected better resistance of crumb rubber modified bitumen to aging as it showed lower value after short-term aging, RTFOT, and long-term aging (PAV), respectively. Thus, the use of viscosity index eliminated the variability caused by difference in viscosity of the original bitumen and modified bitumen which provided a more reliable picture of the hardening (aging) rate.

(4) Furthermore, the higher crumb rubber content, the lower $G^{*} \sin \delta$ at $31^{\circ} \mathrm{C}$ after PAV aging, which led to higher resistance to fatigue cracking.

(5) Crumb rubber modifier increased the stiffness of the bitumen binder improving its resistance to rutting.

\section{References}

[1] J. C. Petersen, "Chemical composition of asphalt as related to asphalt durability-state of the art," Transportation Research Record, vol. 999, pp. 13-30, 1984.

[2] D. R. Brown, D. Jared, C. Jones, and D. Watson, "Georgia's experience with crumb rubber in hot-mix asphalt," Journal of Transportation Research Record, vol. 1583, pp. 45-51, 1997.

[3] G. W. Maupin Jr., "Hot mix asphalt rubber applications in Virginia," Journal of Transportation Research Record, vol. 1530, pp. 18-24, 1996.

[4] E. Charania, J. O. Cano, and R. H. Schnormeier, "Twentyyear study of asphalt rubber pavement in Phoenix, Arizona," Transportation Research Board, vol. 1307, pp. 29-38, 1991.

[5] M. Stroup-Gardiner, B. Chadbourn, and D. E. Newcomb, "Babbitt, Minnesota: case study of pretreated crumb rubber modified asphalt concrete," Transportation Research Record, vol. 1530, pp. 34-42, 1996.

[6] A. A. Mohamed, O. Husaini, M. O. Hamzah, and H. Ismail, "Rheological properties of crumb rubber modified bitumen containing antioxidant," The Arabian Journal For Science and Engineering, vol. 34, article 1B, 2009.

[7] M. Abdelaziz and M. R. Karim, "Rheological evaluation of ageing properties of rubber crumb modified bitumen," Journal of the Eastern Asia Society for Transportation Studies, vol. 5, pp. 820-833, 2003.

[8] S. Liu, W. Cao, J. Fang, and S. Shang, "Variance analysis and performance evaluation of different crumb rubber modified (CRM) asphalt," Construction and Building Materials, vol. 23, no. 7, pp. 2701-2708, 2009.

[9] S. J. Lee, C. K. Akisetty, and S. N. Amirkhanian, “The effect of crumb rubber modifier (CRM) on the performance properties of rubberized binders in HMA pavements," Construction and Building Materials, vol. 22, no. 7, pp. 1368-1376, 2008.

[10] K. D. Jeong, S. J. Lee, S. N. Amirkhanian, and K. W. Kim, "Interaction effects of crumb rubber modified asphalt binders," Construction and Building Materials, vol. 24, no. 5, pp. 824-831, 2010.

[11] L. Raad and S. Saboundjian, "Fatigue behavior of rubber-modified pavements," Transportation Research Record, vol. 1639, pp. 73-82, 1998 .

[12] H. R. Soleymani, H. Zhai, and H. Bahia, "Role of modified binders in rheology and damage resistance behavior of asphalt mixtures," Transportation Research Record, vol. 1875, pp. 70-79, 2004.

[13] S. Aflaki and M. Memarzadeh, "Using two-way ANOVA and hypothesis test in evaluating crumb rubber modification (CRM) agitation effects on rheological properties of bitumen," Construction and Building Materials, vol. 25, no. 4, pp. 20942106, 2011.

[14] H. U. Bahia and D. A. Anderson, "Glass transition behavior and physical hardening of asphalt binders," Journal of the Association of Asphalt Paving Technologists, vol. 62, pp. 93-129, 1993.

[15] X. Lu and U. Isacsson, "Effect of ageing on bitumen chemistry and rheology," Construction and Building Materials, vol. 16, no. 1, pp. 15-22, 2002.

[16] The Asphalt Institute, Performance Graded Asphalt Binder Specification and Testing, Superpave Series (SP-1), Lexington, Lexington, Ky, USA, 2003.

[17] P. Cong, S. Chen, J. Yu, and S. Wu, "Effects of aging on the properties of modified asphalt binder with flame retardants," 
Construction and Building Materials, vol. 24, no. 12, pp. 25542558, 2010.

[18] M. N. Siddiqui and M. F. Ali, "Studies on the aging behavior of the Arabian asphalts," Fuel, vol. 78, no. 9, pp. 1005-1015, 1999.

[19] A. K. Apeagyei, "Laboratory evaluation of antioxidants for asphalt binders," Construction and Building Materials, vol. 25, no. 1, pp. 47-53, 2011. 

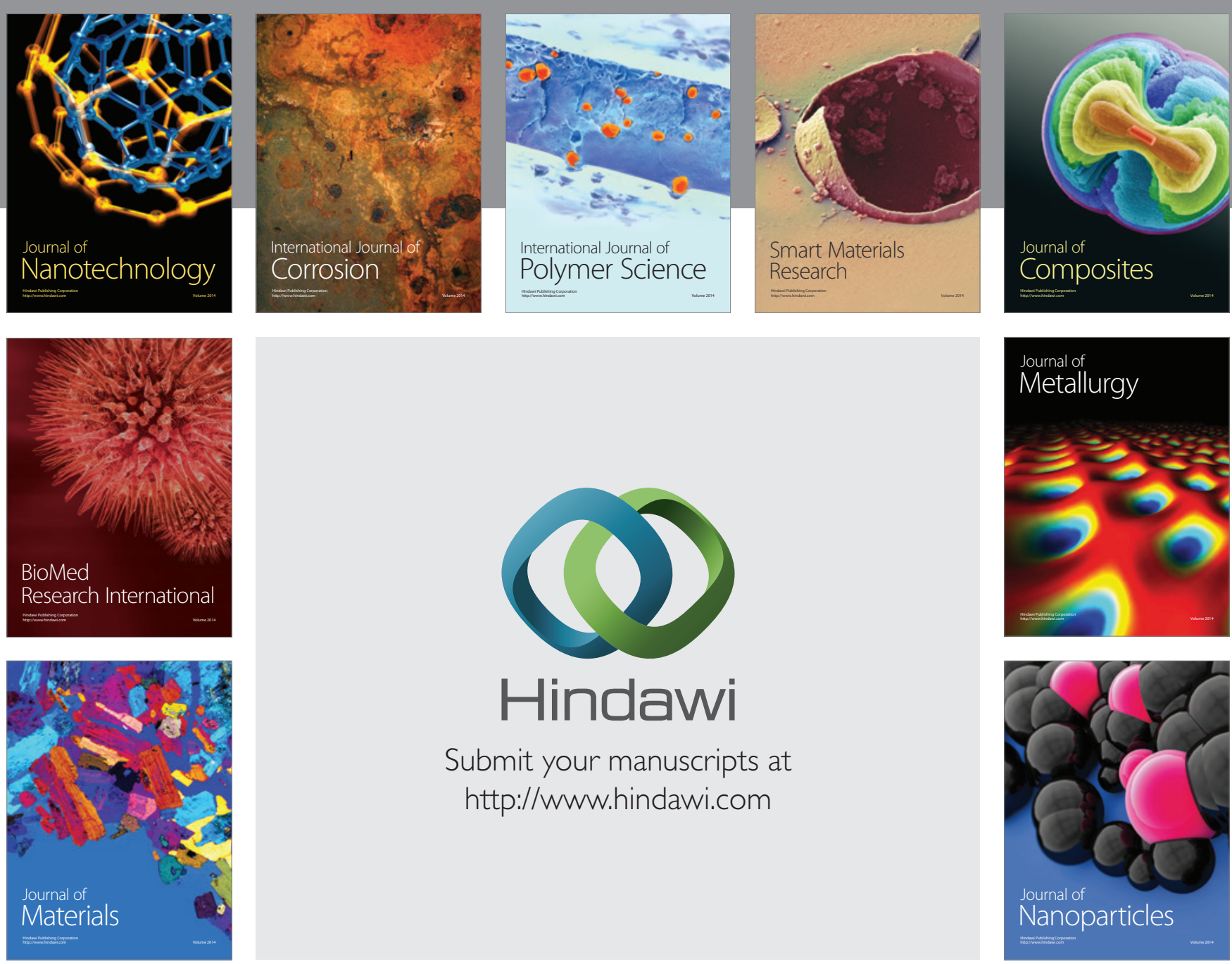

Submit your manuscripts at http://www.hindawi.com
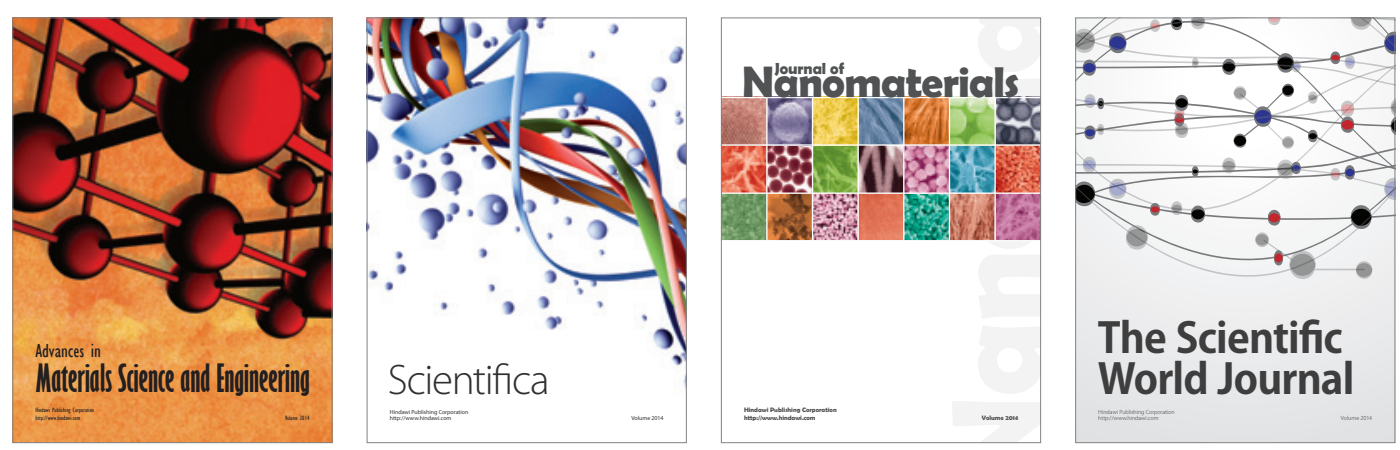

\section{The Scientific World Journal}
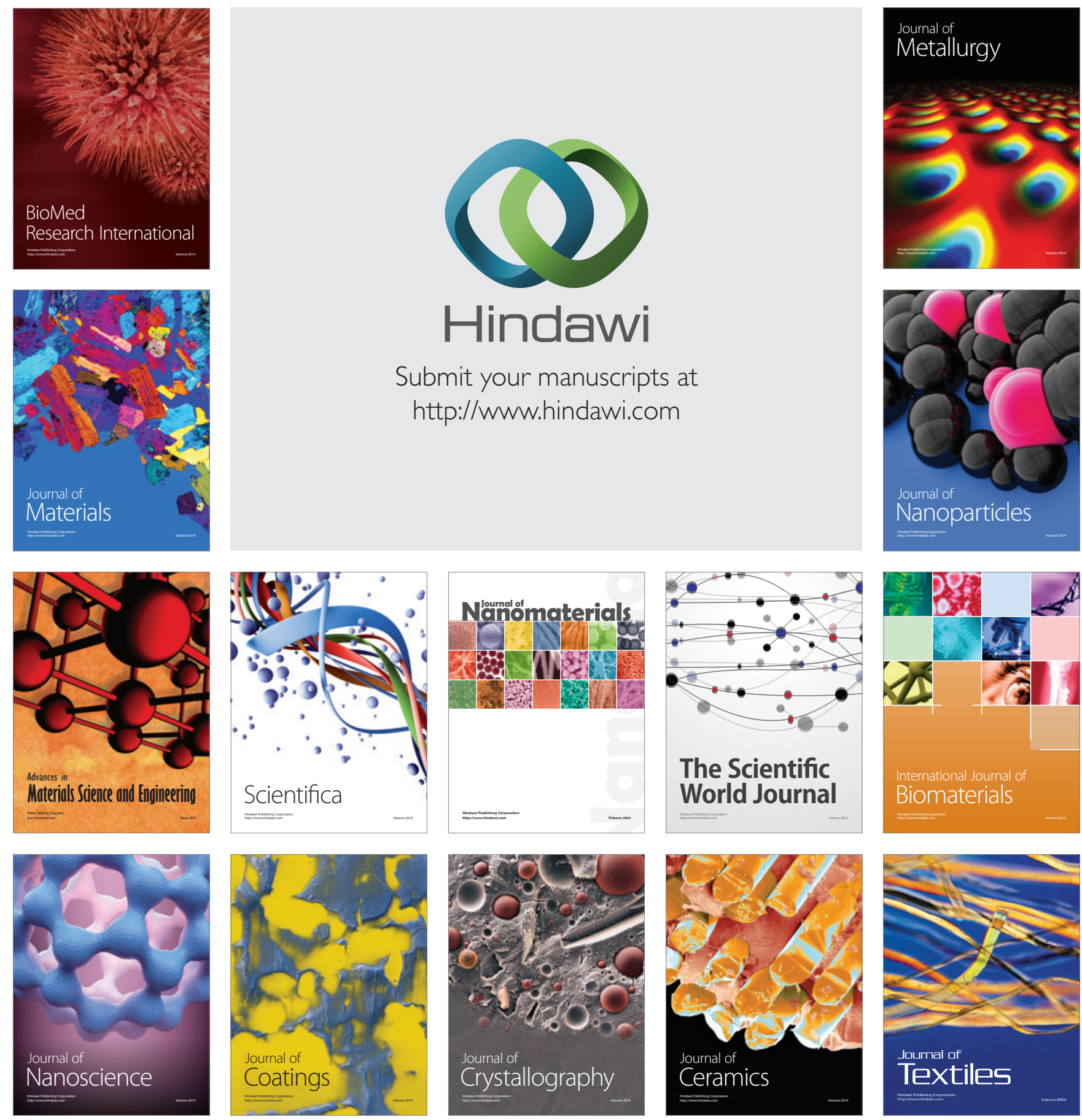